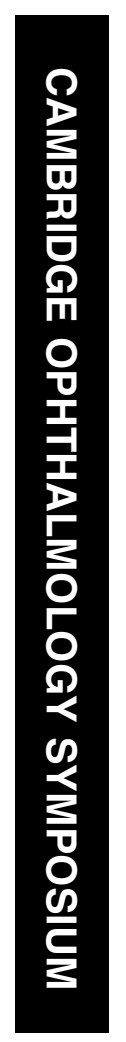

\section{Stem cell therapy and the retina}

\begin{abstract}
Retinal degeneration culminating in photoreceptor loss is the leading cause of untreatable blindness in the developed world. In this review, we consider how photoreceptors might be replaced by transplantation and how stem cells might be optimised for use as donor cells in future clinical strategies for retinal repair. We discuss the current advances in human and animal models of retinal cell transplantation, focussing on stem cell and reproductive cloning biology, in relation to the practical issues of retinal transplantation surgery. Stem and progenitor cells can be isolated from a number of sources including embryonic tissue, adult brain and even the retina, prompting many researchers to investigate the potential for using these cells to generate photoreceptors for transplantation.

Nevertheless, several obstacles need to be overcome before these techniques can be applied in a clinical setting. Embryonic or stem cells have so far shown little ability to differentiate into retinal phenotypes when transplanted into the adult retina. We have recently noted, however, that donor cells harvested much later, at the photoreceptor precursor developmental stage, can be transplanted successfully and restore visual function. The current challenge is to understand the developmental processes that guide embryonic or adult stem cells towards photoreceptor differentiation, so that large numbers of these cells might be transplanted at the optimal stage. Future advances in reproductive cloning technology could lead to the successful generation of stem cells from adult somatic cells, thereby facilitating auto-transplantation of genetically identical cells in patients requiring photoreceptor replacement.
\end{abstract}

${ }^{1}$ Vitreoretinal Service, Moorfields Eye Hospital, London, UK

${ }^{2}$ Division of Molecular Therapy, UCL Institute of Ophthalmology, University College London, London, UK

${ }^{3}$ Developmental Biology Unit, UCL Institute of Child Health, University College London, London, UK

Correspondence: RE MacLaren, Moorfields Eye Hospital, 162 City Road, London EC1V 9EL, UK Tel: + 440207608 4023: Fax: + 442072533411 E-mail:mol.therapy@ ucl.ac.uk

Received: 12 March 2007 Accepted: 21 March 2007

Lecture delivered at the 2006 Cambridge Symposium
Eye (2007) 21, 1352-1359; doi:10.1038/sj.eye.6702842

Keywords: photoreceptor; regeneration; transplantation; development; optic nerve; eye

\section{Introduction}

For most retinal diseases, the loss of retinal neurons is generally regarded to be the irreversible cause and endstage of blindness. Any strategy to restore sight in these cases would almost certainly require cell replacement or transplantation. Although significant developments have been made with electronic implants over recent years, ${ }^{1}$ there will still need to be an interface between electronic hardware and biological tissues at some point along the visual pathway. This will be highly complex. Conversely, however, the synaptic reconnection of transplanted embryonic neurons, or following axonal regeneration along a peripheral nerve graft, is an innate biological property that requires little manipulation. Although electronic devices are extremely effective at converting the visual image into a series of electrical impulses, ${ }^{1}$ the issue of reconnection will be paramount for restoring sight. This will almost certainly make a cell-based approach far more feasible in practical terms as a potential clinical treatment.

Cell replacement by transplantation would be relevant to age-related macular degeneration (AMD), the single commonest cause of blindness in the UK and which causes visual impairment in about one quarter of a million people. ${ }^{2}$ Although promising new treatments for exudative AMD are being developed, such as molecular inhibition of choroidal new vessels, ${ }^{3}$ many patients will still suffer progressive photoreceptor loss, as will those with geographic atrophy. Replacement of the diseased retinal pigment epithelium (RPE) can also prevent loss of sight in some patients with $\mathrm{AMD},{ }^{4}$ but this can be achieved by transplantation of autologous tissue and RPE cells do not require synaptic reconnection. For RPE replacement, traditional transplantation surgery rather than anything complex using stem cells, may be all that would be necessary. Despite these technical advances, however, one over-riding principle remains unchallenged by 
any current treatment: the restoration of vision will always be limited in the face of marked photoreceptor loss. ${ }^{5}$ Similarly, while gene therapy is being successfully developed for inherited retinal diseases, such as retinitis pigmentosa and Leber's congenital amaurosis, it is unlikely to be effective once the affected cells (rods and cones) have degenerated. Ultimately photoreceptor loss represents the final and 'irreversible' end stage of virtually all retinal diseases, with the exception of glaucoma, which is focused on the ganglion cell. Replacement of lost photoreceptors by cell transplantation offers an alternative therapeutic approach in the development of new treatments for retinal disease.

Stem cells, with their capacity for proliferative expansion and the potential to generate multiple cell types, have been proposed as a potential source of cells for neuronal transplantation. The isolation of these cells and methods of transplantation will be discussed here. It is worth noting that photoreceptor replacement is considerably more straightforward than with virtually all other neurons. This is because the photoreceptor is a sensory neuron. It is connected in only one direction (to the horizontal-bipolar cell ribbon) and does not require complex dendritic synapses to generate afferent inputs, because it responds to an external afferent stimulus, light. Developing a stem cell approach for photoreceptor transplantation may therefore present a far more achievable goal than might be the case for ganglion cell replacement, which would require remodelling of complex afferent inputs within the retina, reconnection over long distances to downstream targets and complex navigation. ${ }^{6}$

In considering the potential of what would still be highly complex biological treatment, it is often insightful to start with the clinical scenario and look back towards the most relevant areas of scientific advancement.

Although the distance between theory and practice is still considerable, it may be possible at least to identify the direction the scientific research should follow in order to achieve the clinical goal. With regard to photoreceptor transplantation, the problem can therefore be viewed from two standpoints. First, how to generate appropriate donor cells for transplantation (stepping forwards from the current scientific domain). Ideally to avoid rejection, these cells should be genetically identical to the recipient, which might in theory be achieved either by cloning photoreceptors from adult somatic cells, or by culturing, and differentiating adult stem cell populations, each derived from the patient (see below). Alternatively donor cells from a laboratory stem cell line might be genetically modified to become photoreceptors. Converting stem cells into photoreceptors is a challenging area of basic science that requires considerable expertise in cloning and developmental biology. Second, one has to consider the clinical scenario and the challenges presented by the task of trying to reconnect these cells if they became available (stepping backwards from the future clinical domain). This includes the technical aspects of transplanting cells into a degenerating retina, reconnecting to the host retina and restoring visual function. In this brief review we shall therefore examine both ends of the problem, biological and surgical: first, how to create photoreceptors and second, how to transplant them.

\section{Generating Photoreceptor Cells from Foetal Tissue}

One potential source of donor photoreceptors would be to harvest them from a foetal retina at the exact time when these cells are born and about to form their intrinsic connections. Foetal neurons appear better able to survive transplantation surgery than adult neurons. ${ }^{7-9}$ Previous studies have shown that, before the formation of synaptic connections, retinal ganglion cells can regenerate after axotomy and navigate through the optic chiasm. ${ }^{10}$ Similar studies in the spinal cord have confirmed that developing neurons (during the growth phase after terminal mitosis) have a high degree of plasticity and are able to form reconnections after injury. ${ }^{11,12}$ When transplanted onto the tectum, explants of rodent foetal retinal tissue have demonstrated a capacity to reconnect to targets in the mature central nervous system (CNS) and restore the light pupil constriction reflex. ${ }^{8}$ It would therefore seem logical to assume that immature photoreceptors might also have the capacity to reconnect to adult CNS structures, if these cells could be transplanted in such a way that would optimise their capacity for survival.

One strategy has been to transplant whole sheets of foetal neural retina into the sub-retinal space. Early experiments in rodent models demonstrated that transplantation of whole retinal sheets, derived from either embryonic or neonatal sources, results in the survival and differentiation of the grafted tissue. ${ }^{13-15}$ Similarly, transplants of micro-aggregates from early post-natal retina develop many of the characteristics of retinal cells, including cells that express rhodopsin. ${ }^{16,17}$ However, in each case the transplanted cells identified had integrated to a very limited extent and only rarely made connections with the host tissue, although this may have been the result of poor labelling of photoreceptor processes before the development of fluorescent transgenic mice for use as donors. Some studies have described an improvement in visual function, although this is generally attributed to enhanced survival of endogenous photoreceptor via non-specific trophic signals from the grafted tissue. ${ }^{16-18}$ 
There are a number of potential explanations for why the transplantation of whole sheets of foetal neural retina has been largely unsuccessful. A full-thickness sheet of foetal retina presents a physical challenge to photoreceptor viability. First, the inner retinal neurons are already born in the late developing retina and may interfere with photoreceptors trying to reconnect to the host inner nuclear layer. Second, it would result in a 'double sandwich' of retina. Placed in the subretinal space, the transplanted tissue would separate the host outer nuclear layer (ONL) from the host RPE and any surviving host photoreceptors would most likely become non-functional as a result. A further problem is that the inner part of the transplanted tissue would be ganglion cell and displaced amacrine cells. It is difficult to imagine how these cells could reform functional connections with host bipolar cells or outer nuclear cells of the surviving host retina, although some evidence of synaptic connectivity has been shown previously following retinal slice transplantation in mice with early onset photoreceptor degeneration. ${ }^{19}$ Ideally, a retinal sheet transplant would need to have the inner retinal components removed and a method has been described of slicing live retina tangentially to obtain a sheet of photoreceptors suitable for transplantation. ${ }^{20}$ This could provide a large density of orientated photoreceptors already arranged in a regular array and might be the ideal method for photoreceptor replacement in cases where the host ONL has degenerated completely. Human experiments using subretinal electronic implants have revealed that inner retinal components survive in end-stage retinitis pigmentosa and patients retain a retinotopic map if the retina can be stimulated appropriately. ${ }^{1}$ It remains to be seen if transplanted sheets of foetal photoreceptors could wire-up sufficiently to replicate these effects.

\section{Generating Photoreceptors from Stem Cells}

An alternative strategy has been to examine the potential of cell transplantation, the expectation being that dissociated cells would be better able to migrate into and integrate within the host neural retina, compared to a transplanted slice of retinal tissue. Stem cells, with their greater plasticity and migratory capacity have been proposed as an ideal candidate donor cell. An embryonic stem cell (ESC) is defined as a cell that can both renew itself by repeated division and differentiate into any one of the 200 or more adult cell types in the human body. An ESC cell arises from the eight-cell stage morula (Figure 1a). Outside of normal development, ESCs have been differentiated in vitro into neural cell types and even pigmented epithelium, ${ }^{21}$ although controlling their differentiation has proven challenging. Several human ESC lines exist and are supported by public research funds. The use of ESCs has significant limitations, including ethical issues, and a risk of teratoma formation, but the chief problem is that we are still struggling to understand the developmental cues that differentiate ESCs into the specific adult cell types required for repair of damaged tissues. Neural stem cells (NSCs) have also been isolated from the adult mammalian (including human) brain. NSCs are the self-renewing, multipotent cells that generate the main phenotypes of the nervous system. In 1992, Reynolds and Weiss ${ }^{22}$ were the first to
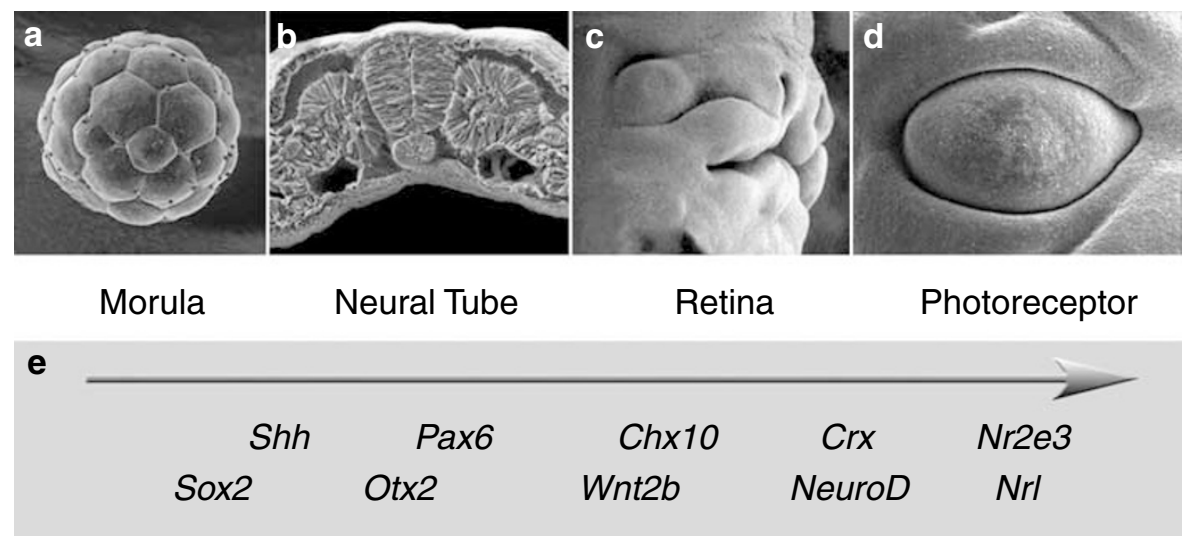

Figure 1 From stem cell to photoreceptor: transcription factors regulate development of the eye. (a) Embryonic stem cells are harvested from the morula - each cell at this stage would have the potential to form a whole embryo. (b) Neurulation at the end of the third week of human development - specification of neural tube and neural crest progenitors. (c) At 5 weeks the primitive eye structures including retinal progenitor cells have formed. (d) By 10 weeks the outer retinal cells are undergoing terminal mitosis to differentiate into cones (and later rods). (e) Some of the transcription factors identified in relation to photoreceptor development and their approximate equivalent expression profile in humans. 
Box 1

\begin{tabular}{|c|c|c|c|}
\hline Type of stem cell & Location & Function & Differentiation capacity \\
\hline Embryonic stem cell & Eight-cell stage morula & Formation of the embryo & $\begin{array}{l}\text { Totipotent (any adult cell } \\
\text { type) }\end{array}$ \\
\hline Neural stem cell & $\begin{array}{l}\text { Subventricular zone of the } \\
\text { adult brain }\end{array}$ & $\begin{array}{l}\text { Maintenance of the rostral } \\
\text { olfactory migratory stream }\end{array}$ & $\begin{array}{l}\text { Olfactory neurons, myocytes, } \\
\text { other neuronal cells }\end{array}$ \\
\hline Retinal stem cell & $\begin{array}{l}\text { Anterior uveal region of the } \\
\text { eye }\end{array}$ & $\begin{array}{l}\text { Presumed to be of } \\
\text { evolutionary significance only }\end{array}$ & $\begin{array}{l}\text { Primitive neuronal cells, } \\
\text { possibly photoreceptors }\end{array}$ \\
\hline Haemopoetic stem cell & $\begin{array}{l}\text { Medullary cavity of the long } \\
\text { bones and vertebrae }\end{array}$ & $\begin{array}{l}\text { Regeneration of circulating } \\
\text { blood cells }\end{array}$ & $\begin{array}{l}\text { Blood cells, possibly other cell } \\
\text { types }^{\text {a }}\end{array}$ \\
\hline Limbal stem cell & $\begin{array}{l}\text { Crypts located deep to the } \\
\text { corneal limbus }\end{array}$ & $\begin{array}{l}\text { Regeneration of the corneal } \\
\text { epithelium }\end{array}$ & $\begin{array}{l}\text { Corneal epithelial cells } \\
\text { (mesenchymal cells in vitro) }\end{array}$ \\
\hline
\end{tabular}

a Previous experiments suggested that haemopoetic stem cells could differentiate into neuronal (Purkinje) cells, but these were subsequently shown to arise by fusion of the stem cell with the existing adult cell to create a hybrid cell expressing both stem cell and adult cell markers. ${ }^{46,47}$

isolate NSCs from the striatal tissue, including the subventricular zone of adult mice brain tissue. Since then, NSCs have been isolated from various areas of the adult brain, including the eye. The discovery of a population of stem cells with neurogenic potential in the adult ciliary margin of the mouse and human eye, ${ }^{23,24}$ raises the intriguing possibility of auto-transplantation that would avoid the problem of rejection and without cloning (see below). Other stem cell populations relevant to the eye are illustrated in Box 1.

A number of studies have investigated retinal transplantation of various types of stem cells. While neural stem cells transplanted into adult retina have shown some evidence of being able to integrate into the host retina, they have thus far failed to differentiate into retinal phenotypes. ${ }^{25,26}$ Conversely, retinal-derived stem cells differentiate into retinal phenotypes but appear to lack the ability to migrate and integrate with the host adult neural retina. ${ }^{27-30}$ Perhaps this is not so surprising; the cues required to guide a stem cell down the multiple developmental steps to becoming a fully differentiated photoreceptor are numerous and complex (Figure 1) and the adult retinal environment may be unable to provide such cues. We re-examined this problem by assessing whether or not retinal stem/progenitor cells from a range of developmental ages could successfully regenerate photoreceptors in mice. We discovered that transplantation and subsequent restoration of visual function is possible, but only when the donor cells are at a specific stage of development: that is when they are already committed to a photoreceptor fate (Figure 2). ${ }^{31}$

These findings define the optimal stage at which a donor cell should be, to have the best chance of successfully integrating within a recipient retina. However, these findings will be hard to translate directly to the clinic. An equivalent staged donor cell in the human would have to come from a second trimester foetus. Once again, the ethical, availability, and rejection issues surrounding such a source prompt us to look for
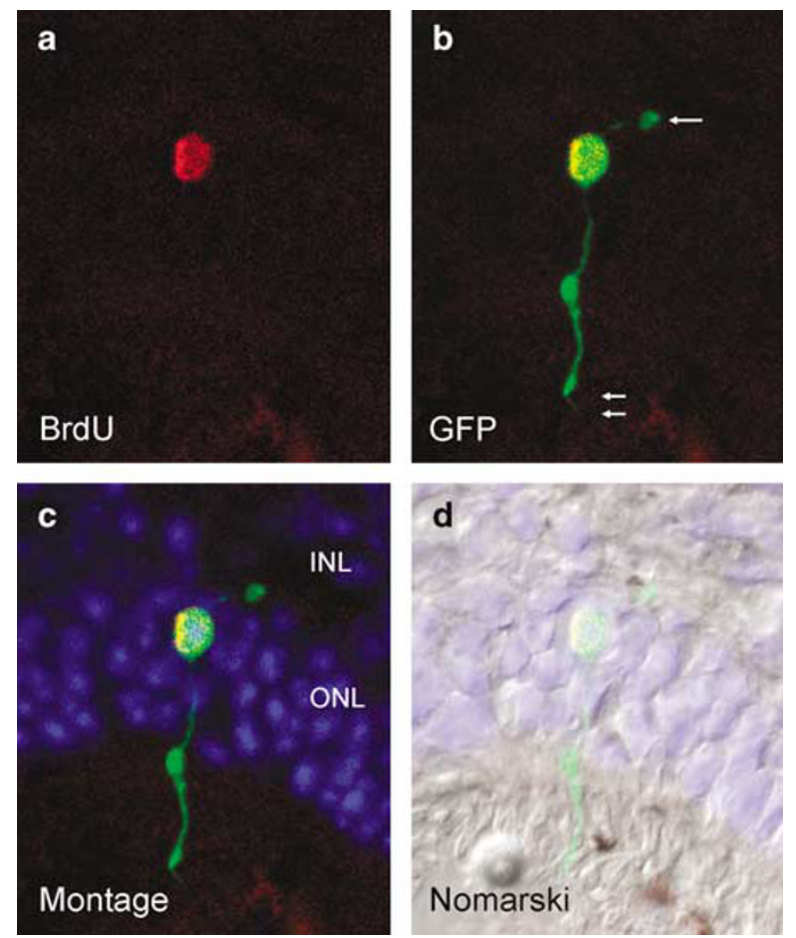

Figure 2 Integrated photoreceptor in the mouse retina 3 weeks after transplantation. ${ }^{31}$ (a) The nucleus of the transplanted photoreceptor was labelled with bromo-deoxyuridine given to the newborn donor mouse $18 \mathrm{~h}$ before transplantation. The donor mouse was a transgenic strain expressing green fluorescent protein (GFP). (b) The morphology of the transplanted cell can be seen by the cytoplasmic distribution of the GFP. Note the developed synapse proximally (single arrow) and thin cilium distally (double arrow). (c) The montage including a blue nuclear stain shows the transplanted photoreceptor in the correct orientation in the host ONL, with inner and outer segments visible in the combined Nomarski image in (d).

alternatives. An attractive avenue of investigation is to try and differentiate stem cells (adult, or potentially embryonic, if ethical issues can be resolved) into photoreceptors in vitro, before transplantation. It is likely 
a $\mathrm{Nrl}$

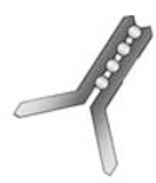
TATA BP RNA Pol-2

b

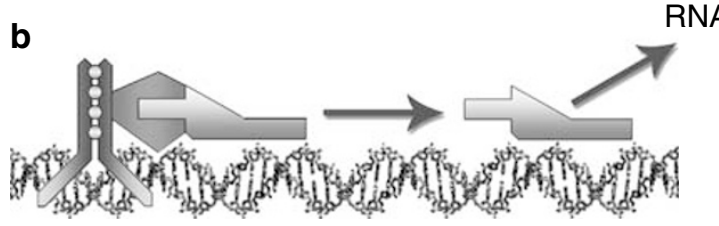
TATA

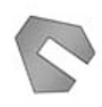

Rod-specific genes
Figure 3 Schematic to illustrate the interaction of transcription factors in photoreceptor development. (a) Nrl (neural leucine zipper) is a folded protein that binds to a specific DNA nucleotide sequence upstream of rod-related genes. ${ }^{40}$ TATA binding protein is part of a family of general transcription factor proteins that bind to regions of DNA rich in TA nucleotides known as the TATA box. This is generally found 25 nucleotides upstream of each gene and because T-A base pairing exerts less force than G-C, the DNA in these regions can be separated more easily. RNA Polymerase II ( $\mathrm{Pol} 2$ ) binds to the unpaired sense strand of DNA to read off the RNA for each gene. (b) The assembly of the transcription factors upstream of specific genes therefore guides RNA polymerase II to specific regions of the genome. Here $\mathrm{Nrl}$ recognises the DNA sequences upstream of the rhodopsin gene. Transcription factors activate developmental genes that are vital for defining the adult cell type but also have an important role in adult cell maintenance. Hence mutations in $\mathrm{Nrl}$ (or $\mathrm{Nr} 2 \mathrm{e3}$ ) cause abnormalities of photoreceptor development, in addition to rod-cone dystrophies.

that a thorough understanding of photoreceptor developmental biology will be key to the success of such a strategy. Neuronal specification is guided by complex interactions between intrinsic (genetic) programs and extrinsic regulatory factors, and requires the precise coordination between exit from the cell cycle and differentiation. ${ }^{32-34}$ A transcription factor is a small DNA-binding protein that acts as a genetic switch to activate specific genes (Figure 3 ). In a developing cell, a complex series of transcription factors sequentially activates genes involved in development, thus defining the adult cell type. ${ }^{35} \mathrm{~A}$ number of transcription factors involved in the differentiation of photoreceptors have been identified (Figure 1e), but more probably remain to be discovered. Furthermore, we do not yet know how precise the activation of transcription factors needs to be. Do we need one or many switches? Generally, transcription factors act in a cascade and it might be possible to find a 'master control' gene that activates all others required for a photoreceptor.

The Pax- 6 gene encodes a transcription factor controlling ocular development (and causes aniridia when partially deficient in humans). This gene can induce the generation of an entire eye when ectopically expressed on the thorax of the fruit fly. ${ }^{36}$ An equivalent photoreceptor 'master control' gene has not yet been identified. In mammals, Chx10 is one of the earliest markers in the presumptive neural retina of the invaginating optic vesicle. Upon terminal division, its expression is restricted to bipolar and a subpopulation of Müller glial cells in the inner nuclear layer. ${ }^{37}$ Mutations in both the human and mouse Chx10 genes leads to microphthalmia. ${ }^{38} \mathrm{Ch} \times 10$ activates the transcription factor gene Crx, which in turn activates NeuroD and neural retina leucine zipper $(\mathrm{Nrl})$. Crx , NeuroD, Nrl, and $\mathrm{Nr} 2 \mathrm{e} 3$ are the main transcription factors known to be involved in photoreceptor generation thus far. Crx and NeuroD are expressed in photoreceptors of the developing and mature retina, and are essential for correct differentiation and maturation. ${ }^{39} \mathrm{Nrl}$ is exclusively expressed in rod photoreceptors and is indispensable for their development and maintenance (human NRL dominant mutations may cause rod-cone dystrophies). ${ }^{40}$ In vitro studies indicate that Nr2e3 acts synergistically with $\mathrm{Nrl}$ and represses the activation of cone genes by Crx (Human NR2E3 recessive mutations may cause enhanced S-cone syndrome). ${ }^{41,42}$ We do not yet know how precise the timing of these transcription factors needs to be, nor indeed whether certain steps can be bypassed; for example, if expression of $\mathrm{Nrl}$ alone, without prior expression of Chx10 or Crx leads to the generation of photoreceptors from stem cells in vitro. Iris cells, when transduced in vitro with the transcription factors Crx and Ot $x 2$ express rhodopsin, ${ }^{43,44}$ but does that make them photoreceptor cells, or just iris cells that express rhodopsin? Indeed, it is still unclear whether true differentiation of photoreceptors can occur in vitro (which is where a stem cell line would be differentiated) because many of the required developmental cues arise outside the cell in the complex milieu of the primitive eye cup. ${ }^{45}$

\section{Generating Photoreceptors by Therapeutic Cloning}

An attractive means of generating photoreceptors would be to create them from cells already present in the patient. If the photoreceptor were cloned from an adult somatic cell, it would have an identical immune profile and rejection after transplantation would be very unlikely. Cloning, in the reproductive sense, is a technology used to generate an animal with identical nuclear DNA to another currently or previously existing animal. Reproductive cloning is achieved by a process known as somatic cell nuclear transfer (SCNT), in which the DNA from an adult somatic cell is inserted into an oocyte which has had its original chromosomal material removed (Figure 4). The oocyte with its new DNA payload is electrically stimulated and divides, generating 

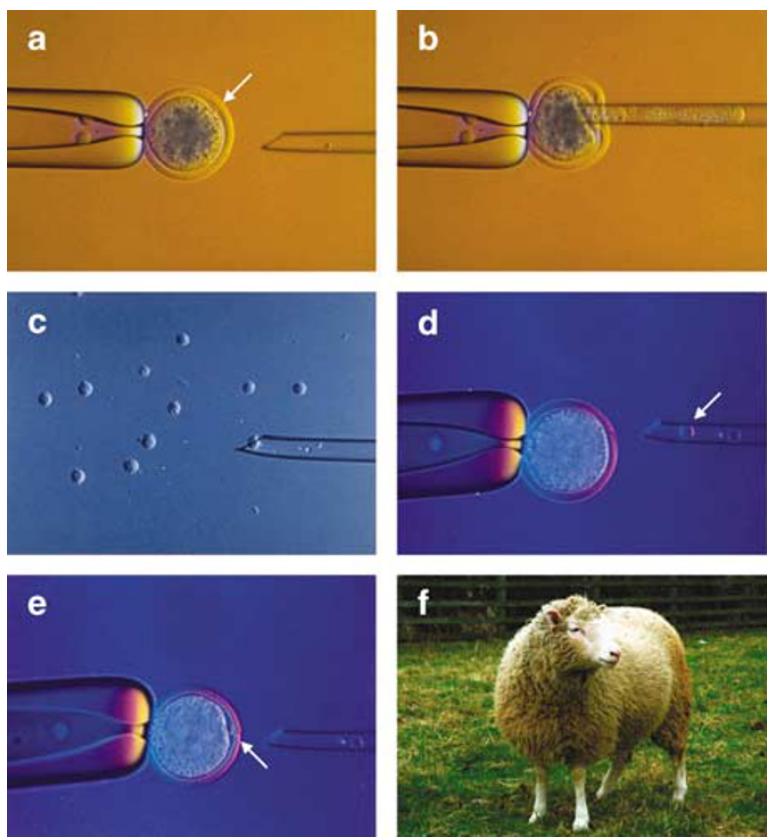

Figure 4 Somatic cell nuclear transfer and cloning. (a) A mature oocyte is arrested in metaphase II. The Barr body (arrow) can be seen. (b) The nucleus (chromosomal DNA) of the oocyte is gently extracted through a micro-pipette. (c) Adult mammary gland cells are cultured in serum free media to arrest growth and enter the $G_{0}$ resting phase before being selected. (d) The mammary gland cell is held in a micro-pipette (arrow), which is advanced towards the original membrane defect of the enucleated oocyte. (e) The mammary gland cell is injected into the oocyte and can be seen just under the zona pellucida (arrow). An electrical impulse subsequently causes nuclear fusion and the oocyte cytoplasm reprograms the new adult DNA to initiate development all over again. (f) Dolly the sheep was the first mammal to be successfully cloned from an adult cell, which was taken from the mammary gland of her genetically identical mother. Photos copyright: Roslin Institute.

ESCs, which can be kept in vitro or implanted into a uterus, applying similar techniques to in vitro fertilisation. The cloning of Dolly the sheep (Figure 4f) 10 years ago represented a major breakthrough, because it proved that the DNA extracted from an adult fully differentiated cell (a mammary gland cell) could be reprogrammed by the oocyte to give rise to any of the different cell types within the sheep. ${ }^{48}$ Dolly could see which, put simply, meant that DNA from a mammary gland cell of the donor sheep had been reprogrammed to become the DNA of a photoreceptor cell. Until that point, it was widely believed that an adult somatic cell (or its nucleus) once differentiated, could not revert back into a stem cell. We now know that it is possible to create any one of the 200 different cell types in the body by SCNT and these cloned cells (or organs) would be ideal (perfect) genetic matches for transplantation back into the donor animal or patient.
It is of some academic interest to note that the clone is only $99.7 \%$ genetically identical to the original SCNT donor animal, because the mitochondria originate from the fertilised ovum. ${ }^{49}$ This may be relevant for any future therapeutic applications of SCNT in treating mitochondrial disease, because cells cloned for replacement of diseased cells would not contain the mitochondrial DNA mutation of the affected patient, but would otherwise be genetically identical. Adult somatic cells harvested from patients with mitochondrial diseases, such as Kearne's Sayre syndrome or Leber's hereditary optic neuropathy, would most likely lose the defective mitochondrial DNA during the cloning process.

Cloning of primates by SCNT has proven considerably more challenging. To date there are no reports of successful monkey (or human) cloning by using DNA from an adult donor cell. Essentially primate oocytes seem to be unable to reprogram adult DNA when fused with primate somatic cell nuclei. The reasons for this are not clear, but may lie in the complexity of epigenetic mechanisms, such as DNA methylation and histone acetylation. ${ }^{50}$ These DNA modifications regulate gene expression in a similar way to $\mathrm{X}$ chromosome inactivation, and it may be that the epigenetic changes in adult primate DNA are simply too complex to be reversed. ${ }^{51}$ In successfully cloned non-primate mammals, however, factors released by the oocyte cytoplasm appear to have remarkable control of somatic DNA, either in restoring telomere length, ${ }^{52}$ or in reprogramming of $\mathrm{X}$-inactivation. ${ }^{53}$ Understanding the mechanism whereby oocyte cytoplasm controls somatic nuclear differentiation will almost certainly be the key to successful cloning of adult primate cells for autotransplantation. This is currently problematic, but much research is still ongoing at the next stage, which is to take an embryonic dividing (stem) cell and differentiate it into a photoreceptor.

\section{Conclusion}

It is likely that exploitation of stem cells will require a deeper understanding of developmental biology and the identification of key regulators in the photoreceptor differentiation pathway. Stem cell-based therapies are currently the subject of intense investigation and debate. As a field we must be careful when identifying the prospects that each type of cell might offer. Specifically, we must be rigorous in our assessments of the outcomes of transplantation experiments, including full identification of the cell types generated and their impact on visual function.

The translation of stem cell biology into a clinical treatment for photoreceptor transplantation might therefore follow a hypothetical path across three overlapping phases of research. Phase 1 would be to 
extract DNA from an adult cell and clone it into an oocyte by somatic cell nuclear transfer and stimulate the cell to undergo mitosis and become an ESC. Phase 2 would be to expand and differentiate the stem cell in vitro into millions of embryonic photoreceptor cells, possibly using exogenously applied induction signals or transcription factors. Phase 3 would be to develop the surgical means whereby the embryonic photoreceptor cells could be transplanted in such a way that would allow their integration with host horizontal-bipolar cell synapses and restoration of visual function. Our recent observations suggest that the final step is achievable and we await future developments in cloning and stem cell biology with great interest.

\section{Acknowledgements}

The authors are generously supported by grants from the Health Foundation, the Medical Research Council (UK), The Royal College of Surgeons of Edinburgh, the Scottish National Institution for the War Blinded, the Royal National Blind Asylum and School, and the Special Trustees of Moorfields Eye Hospital.

\section{References}

1 Humayun MS, Weiland JD, Fujii GY, Greenberg R, Williamson R, Little $\mathrm{J}$ et al. Visual perception in a blind subject with a chronic microelectronic retinal prosthesis. Vision Res 2003; 43: 2573-2581.

2 Chopdar A, Chakravarthy U, Verma D. Age-related macular degeneration. BMJ 2003; 326: 485-488.

3 Rosenfeld PJ, Brown DM, Heier JS, Boyer DS, Kaiser PK, Chung $\mathrm{CY}$ et al. Ranibizumab for neovascular age-related macular degeneration. $N$ Engl J Med 2006; 355: 1419-1431.

4 Joussen AM, Heussen FMA, Joeres S, Llacer H, Prinz B, Rohrschneider $\mathrm{K}$ et al. Autologous translocation of the choroid and retinal pigment epithelium in age-related macular degeneration. Am J Ophthalmol 2006; 142: 17-30.

5 MacLaren RE, Bird AC, Sathia PJ, Aylward GW. Long-term results of submacular surgery combined with macular translocation of the retinal pigment epithelium in neovascular age-related macular degeneration. Ophthalmology 2005; 112: 2081-2087.

6 MacLaren RE. Re-establishment of visual circuitry after optic nerve regeneration. Eye 1999; 13: 277-284.

7 MacLaren RE, Taylor JSH. Regeneration in the developing optic nerve: Correlating observations in the opossum to other mammalian systems. Prog Neurobiol 1997; 53: 381-398.

8 Klassen H, Lund RD. Retinal transplants can drive a pupillary reflex in host rat brains. Proc Natl Acad Sci USA 1987; 84: 6958-6960.

9 Radel JD, Kustra DJ, Das S, Elton S, Lund RD. The pupillary light response: Assessment of function mediated by intracranial retinal transplants. Neuroscience 1995; 68: 909-924.

10 MacLaren RE, Taylor JSH. Chiasmatic specificity in the regenerating mammalian optic nerve. Exp Neurol 1997; 147: 279-286.
11 Bradbury EJ, McMahon SB. Spinal cord repair strategies: why do they work? Nat Rev Neurosci 2006; 7: 644-653.

12 Filbin MT. Recapitulate development to promote axonal regeneration: good or bad approach? Philos Trans $R$ Soc Lond B Biol Sci 2006; 361: 1565-1574.

13 Seiler M, Aramant RB, Ehinger B, Adolph AR. Transplantation of embryonic retina to adult retina in rabbits. Exp Eye Res 1990; 51: 225-228.

14 Zhang Y, Caffe AR, Azadi S, van Veen T, Ehinger B, Perez MT. Neuronal integration in an abutting-retinas culture system. Invest Ophthalmol Vis Sci 2003; 44: 4936-4946.

15 Ghosh F, Ehinger B. Full-thickness retinal transplants: a review. Ophthalmologica 2000; 214: 54-69.

16 Gouras P, Du J, Gelanze M, Lopez R, Kwun R, Kjeldbye H, Krebs W. Survival and synapse formation of transplanted rat rods. J Neural Transplant Plast 1991; 2: 91-100.

17 Gouras P, Du J, Kjeldbye H, Yamamoto S, Zack DJ. Long-term photoreceptor transplants in dystrophic and normal mouse retina. Invest Ophthalmol Vis Sci 1994; 35: 3145-3153.

18 Klassen HJ, Ng TF, Kurimoto Y, Kirov I, Shatos M, Coffey P, Young MJ. Multipotent retinal progenitors express developmental markers, differentiate into retinal neurons, and preserve light-mediated behavior. Invest Ophthalmol Vis Sci 2004; 45: 4167-4173.

19 Kwan ASL, Wang S, Lund RD. Photoreceptor layer reconstruction in a rodent model of retinal degeneration. Exp Neurol 1999; 159: 21-33.

20 Khodair MA, Zarbin MA, Townes-Anderson E. Cyclic AMP prevents retraction of axon terminals in photoreceptors prepared for transplantation: an in vitro study. Invest Ophthalmol Vis Sci 2005; 46: 967-973.

21 Haruta M, Sasai Y, Kawasaki H, Amemiya K, Ooto S, Kitada $\mathrm{M}$ et al. In vitro and in vivo characterization of pigment epithelial cells differentiated from primate embryonic stem cells. Invest Ophthalmol Vis Sci 2004; 45: 1020-1025.

22 Reynolds BA, Weiss S. Generation of neurons and astrocytes from isolated cells of the adult mammalian central nervous system. Science 1992; 255: 1707-1710.

23 Tropepe V, Coles BLK, Chiasson BJ, Horsford DJ, Elia AJ, McInnes RR et al. Retinal stem cells in the adult mammalian eye. Science 2000; 287: 2032-2036.

24 Ahmad I, Tang L, Pham H. Identification of neural progenitors in the adult mammalian eye. Biochem Biophys Res Commun 2000; 270: 517-521.

25 Takahashi M, Palmer TD, Takahashi J, Gage FH. Widespread integration and survival of adult-derived neural progenitor cells in the developing optic retina. Mol Cell Neurosci 1998; 12: 340-348.

26 Young MJ, Ray J, Whiteley SJ, Klassen H, Gage FH. Neuronal differentiation and morphological integration of hippocampal progenitor cells transplanted to the retina of immature and mature dystrophic rats. Mol Cell Neurosci 2000; 16: 197-205.

27 Chacko DM, Rogers JA, Turner JE, Ahmad I. Survival and differentiation of cultured retinal progenitors transplanted in the subretinal space of the rat. Biochem Biophys Res Commun 2000; 268: 842-846.

28 Sakaguchi DS, Van Hoffelen SJ, Theusch E, Parker E, Orasky J, Harper MM et al. Transplantation of neural progenitor cells into the developing retina of the Brazilian opossum: an in vivo system for studying stem/progenitor cell plasticity. Dev Neurosci 2004; 26: 336-345. 
29 Van Hoffelen SJ, Young MJ, Shatos MA, Sakaguchi DS. Incorporation of murine brain progenitor cells into the developing mammalian retina. Invest Ophthalmol Vis $\mathrm{Sci}$ 2003; 44: 426-434.

30 Yang HS, Standifer KM, Sherry DM. Synaptic protein expression by regenerating adult photoreceptors. J Comp Neurol 2002; 443: 275-288.

31 MacLaren RE, Pearson RA, MacNeil A, Douglas RH, Salt TE, Akimoto $\mathrm{M}$ et al. Retinal repair by transplantation of photoreceptor precursors. Nature 2006; 444: 203-207.

32 Levine EM, Fuhrmann S, Reh TA. Soluble factors and the development of rod photoreceptors. Cell Mol Life Sci 2000; 57: 224-234.

33 Desai AR, McConnell SK. Progressive restriction in fate potential by neural progenitors during cerebral cortical development. Development 2000; 127: 2863-2872.

34 Dyer MA, Cepko CL. Regulating proliferation during retinal development. Nat Rev Neurosci 2001; 2: 333-342.

35 Levine M, Davidson EH. Gene regulatory networks for development. Proc Natl Acad Sci USA 2005; 102: 4936-4942.

36 Halder G, Callaerts P, Gehring WJ. Induction of ectopic eyes by targeted expression of the eyeless gene in Drosophila. Science 1995; 267: 1788-1792.

37 Rowan S, Chen CM, Young TL, Fisher DE, Cepko CL Transdifferentiation of the retina into pigmented cells in ocular retardation mice defines a new function of the homeodomain gene, Chx10. Development 2004; 131: 5139-5152.

38 Ferda Percin E, Ploder LA, Yu JJ, Arici K, Horsford DJ, Rutherford A et al. Human microphthalmia associated with mutations in the retinal homeobox gene CHX10. Nat Genet 2000; 25: 397-401.

39 Furukawa T, Morrow EM, Cepko CL. Crx , a novel otx-like homeobox gene, shows photoreceptor-specific expression and regulates photoreceptor differentiation. Cell 1997; 91 : 531-541.

40 Mears AJ, Kondo M, Swain PK, Takada Y, Bush RA, Saunders TL et al. Nrl is required for rod photoreceptor development. Nat Genet 2001; 29: 447-452.

41 Chen J, Rattner A, Nathans J. The rod photoreceptor-specific nuclear receptor Nr2e3 represses transcription of multiple cone-specific genes. J Neurosci 2005; 25: 118-129.
42 Haider NB, Jacobson SG, Cideciyan AV, Swiderski R Streb LM, Searby $C$ et al. Mutation of a nuclear receptor gene, NR2E3, causes enhanced $S$ cone syndrome, a disorder of retinal cell fate. Nat Genet 2000; 24: 127-131.

43 Haruta M, Kosaka M, Kanegae Y, Saito I, Inoue T, Kageyama $\mathrm{R}$ et al. Induction of photoreceptor-specific phenotypes in adult mammalian iris tissue. Nat Neurosci 2001; 4: 1163-1164.

44 Akagi T, Mandai M, Ooto S, Hirami Y, Osakada F, Kageyama $\mathrm{R}$ et al. Otx2 homeobox gene induces photoreceptor-specific phenotypes in cells derived from adult iris and ciliary tissue. Invest Ophthalmol Vis Sci 2004; 45: 4570-4575.

45 Bradford RL, Wang C, Zack DJ, Adler R. Roles of cell-intrinsic and microenvironmental factors in photoreceptor cell differentiation. Dev Biol 2005; 286: 31-45.

46 Weimann JM, Johansson CB, Trejo A, Blau HM. Stable reprogrammed heterokaryons form spontaneously in Purkinje neurons after bone marrow transplant. Nat Cell Biol 2003; 5: 959-966.

47 Vieyra DS, Jackson KA, Goodell MA. Plasticity and tissue regenerative potential of bone marrow-derived cells. Stem Cell Rev 2005; 1: 65-69.

48 Wilmut I, Schnieke AE, McWhir J, Kind AJ, Campbell KH. Viable offspring derived from fetal and adult mammalian cells. Nature 1997; 385: 810-813.

49 Evans MJ, Gurer C, Loike JD, Wilmut I, Schnieke AE, Schon EA. Mitochondrial DNA genotypes in nuclear transfer-derived cloned sheep. Nat Genet 1999; 23: 90

50 Yang J, Yang S, Beaujean N, Niu Y, He X, Xie Y et al. Epigenetic marks in cloned rhesus monkey embryos: comparison with counterparts produced in vitro. Biol Reprod 2007; 76: 36-42.

51 Gurdon JB, Byrne JA. The first half-century of nuclear transplantation. Proc Natl Acad Sci USA 2003; 100: 8048-8052.

52 Lanza RP, Cibelli JB, Blackwell C, Cristofalo VJ, Francis MK, Baerlocher GM et al. Extension of cell life-span and telomere length in animals cloned from senescent somatic cells. Science 2000; 288: 665-669.

53 Eggan K, Akutsu H, Hochedlinger K, Rideout W, Yanagimachi R, Jaenisch R. X-chromosome inactivation in cloned mouse embryos. Science 2000; 290: 1578-1581. 